\title{
The Relationship between Incidental Vocabulary Learning and Multiple Intelligences of Iranian EFL Learners
}

\author{
Ali Akbar Khomeijani Farahani \\ University of Tehran, Iran \\ Elnaz Latifi Kalkhoran \\ Islamic Azad University, Science and Research Branch, Iran
}

\begin{abstract}
This study was an attempt to investigate the relationship between Iranian EFL learners' multiple intelligences (MI) and incidental vocabulary learning. The study was conducted in classes of two institutes in Tehran. The participants of the study were 42 Iranian female intermediate EFL learners, selected based on the score that they got on the Nation's Vocabulary Levels Test, and by taking this test, the learners' vocabularies proficiency level were homogenized. Then MIDAS questionnaire investigating eight types of different intelligences was used in this study. In the next stage, a vocabulary pretest which was designed by the researcher and was piloted in the same condition to the main study was conducted prior to the treatment of the study (extensive reading program).when the treatment of the study finished an immediate vocabulary posttest conducted to the same participants. The vocabulary posttest was exactly the same as vocabulary pretest. The results of the study showed that there was a significant relationship between Iranian EFL learners' MI and incidental vocabulary learning and also among the eight different types of intelligences; there was a significant relationship between naturalist and incidental vocabulary learning.
\end{abstract}

Index Terms - incidental vocabulary learning, multiple intelligences, multiple intelligences theory

\section{INTRODUCTION}

Nowadays, as Griffiths (2003) states, the importance of vocabulary and its significant role in language learning has been acknowledged. Vocabulary's prominent role in running a meaningful communication and in second language learning has been revealed day after day (Huckin \& Coady 1999). Gass (1999) believes "learning a second language means learning its vocabulary" (p. 325). "Vocabulary acquisition is a crucial, and in some senses, the central component in successful foreign language acquisition" (Beglar \& Hunt, 2005, p.7). According to Allen (1983), learning the meaning of a new word is a difficult matter which most teachers and learners are aware of.

One of the major controversial issues in vocabulary teaching and learning is how to identity significant approaches and strategies to teaching and learning vocabularies which lead to longer and easier retrieval of vocabularies. There are two main approaches towards teaching and learning vocabulary, one of them is intentional the other one is incidental vocabulary learning. Some of the prominent definitions for incidental vocabulary learning are like the following: Nation (2001) defines incidental vocabulary learning as a learning that happens without specific intention to focus on vocabulary so a learner can get the vocabulary knowledge subconsciously through engaging in language activities, mostly reading. Paribakht and Wesche (1999) state that incidental vocabulary learning happens when learners' attention is on understanding meaning rather than on explicit goal of learning new words. Hulstijin (2011) says that most vocabulary items are acquired incidentally; incidental vocabulary acquisition is a by-product of the learners' engagement in listening, reading or writing activity.

Some decades ago multiple intelligences were often considered as a unified dimension concept which was discussed in disciplines such as psychology, and philosophy. In recent years researchers have paid noticeable attention to multiple intelligences in language pedagogy and syllabus designing that corresponds with the guide lines of multiple intelligences theory. One of the most common definitions of MI is "the capacity to solve problems or to fashion products that are valued in one or more cultural settings" (Gardner \& Hatch, 1989, pp.4-9). Gardner (1983) moots that multiple intelligences theory is a learner-centered theory which contemplates each learner as distinguished individual who has various types of intelligences. He enumerates eight different intelligences: Verbal-Linguistic Intelligence, Logical-Mathematical Intelligence, Visual-Spatial Intelligence, Bodily- Kinesthetic Intelligence, Musical Intelligence, Interpersonal Intelligence, Intrapersonal Intelligence, and Naturalist Intelligence. Nelson (1998) says that educating the students means recognizing that each of them is unique, complex, and highly individualistic. He continues that one of the foundations of Multiple Intelligences theory is to design education that can be responsive to individual cognitive differences. Hoerr (2000) says the multiple intelligences theory, gives an opportunity to teachers to use the students' strength to help them learn. According to Hoerr (2000) it is important to apply MI theory in education because 1) it 
emphasizes on uniqueness of learners. 2) Presents the learners' prominent intelligences which helps to learning process. 3) It provides different opportunities of learning, teaching and assessing. Success of each student in learning process is the main concern of teachers. They seek different methods and influential ways to help their learners. Gardner's (1983) MI theory gives learners chances to overcome learning difficulties.

Using multiple intelligences theory (MIT) in language pedagogy especially in vocabulary learning may help learners to learn words faster by ignoring or strengthening each individual intelligences which means paying attention to uniqueness of students' intelligences. To fulfill the purpose of the study, the following two questions were raised:

- Is there any significant relationship between incidental vocabulary learning and the EFL learners' level of multiple intelligences?

- Is there any significant relationship between incidental vocabulary learning and a specific type of intelligence?

\section{METHOD}

\section{A. Participants}

The participants of the present study were forty two Iranian female intermediate EFL learners whose first language was Persian and they were learning English in two institutes in Tehran. The participants were selected from a pool of sixty five English learners. They were studying English language at the intermediate level and in order to homogenize their vocabularies' proficiency level, they took Nation's Levels Test of vocabulary knowledge. After examining the scores of participants on Nation' Levels Test of vocabulary knowledge a total number of forty two EFL learners were selected to participate in this study. It is essential to mention that the age limitation of the participants varied from 17to 27. This study was conducted for three months in the classes of participants.

\section{B. Instrumentation}

\section{Nation's Vocabulary Levels Test}

In order to homogenize the participants' vocabulary size, a modified version of Nation's (1983 \&1990) Vocabulary Levels Test (VLT) (Schmitt et al., 2001) was conducted. This test was mainly designed by Nation and it has two types one of which measures receptive and the other one the productive vocabulary knowledge. The receptive vocabulary levels test which gages the size of the vocabulary was used in this research. The academic and 10000 levels were excluded from the VLT by the researcher because as it was mentioned the proficiency level of participants' vocabulary knowledge was intermediate. The format of Nation's Vocabulary Levels Test was word-definition matching; it also contained five parts: the 2,000 word level, the 3,000 word level, The 5,000 word level, the academic vocabulary level and the 10000 word level. For interpreting the test, Nation (2008) explains that "each word in the test represents 33 words (1000 divided by 30). A score of 20 out of 30 on a level means that a learner knows 667 words out of the 1000 at that level and does not know 333 from that level. We would expect a learner to know at least $90 \%$ of the words at that level (27 out of 30) before we could feel that the level might be known (p. 143)". About the reliability of the test Qian (2002) reported that the reliability was .91 in a sample of adult English language learners with various native language backgrounds and the internal consistency reliability was .956 in this sample.

\section{Multiple Intelligences Developmental Assessment Scales}

Multiple Intelligences Developmental Assessment Scales (MIDAS) inventory for adults which was developed by Shearer (1996) was used in this study. It provided information to grade intellectual development. It had one hundred and nineteen likert-type items. It covered eight separate intelligences. There was no right or wrong response. Since each item had an "I don't know" or "Does not apply" option, respondents were not forced to answer every question. So they could choose one of these options whenever it was appropriate. Actually it should be mentioned that the Persian translated version of MIDAS was used in this study in order to be sure that there would be no problem in comprehension of the items.

\section{Pretest}

Participants took a pretest of vocabulary to become sure about their level of proficiency in vocabulary. This pretest was designed according to the words which appeared in the determined reading texts prepared for the treatment. Stem of each item was selected from Oxford Advanced Learner Dictionary. It was developed to make sure that the participants had no knowledge of the target words prior to the treatment. The format of pretest was multiple choice test which had four options and it had one hundred and fifty items.

\section{Posttest}

After participants received the treatment of the study (extensive reading program) which took twenty sessions an immediate posttest of vocabulary was administered the next session (three days later). The pretest and posttest were exactly identical. During taking the pretest and posttest the learners were instructed not to use dictionary.

\section{Text}

Texts were selected from "English through reading touching story" that was based on three levels of proficiency, which the intermediate one was used in this study for the extensive reading program because it was suitable for the participants' proficiency level. So twenty three texts were selected from this book, and they were read aloud in the class by teacher.

\section{Target words}


Among the Twenty Three texts which were presented in the treatment of the study, one hundred and fifty words were selected that participants encountered them in the determined texts. Before starting the research these one hundred and fifty words in a form of multiple choice test were administered among eighty intermediate level students. There was no item that almost all participants could answer it correctly. According to Hu and Nation (2000) in order to incidentally learn vocabulary through extensive reading program, comprehensible texts should be selected. So they mentioned that if $95 \%-98 \%$ of running words in a text were known to the learner, extensive reading could happen. By this percentage they meant that in every one hundred running words, just two words should be unknown for the readers. The texts which were read in this research were based on this fact.

\section{PROCEDURE}

At first in order to homogenize participants' vocabulary size, Nation's reliable and standard Vocabulary Levels Test was given to participants. This test was one of the equivalent forms of the original one which was revised and validated by Schmitt et al. (2001). The vocabulary pretest and posttest was piloted with 80 intermediate students. They answered to one hundred and fifty items of test. It was also mentioned that they were not allowed to use dictionary during test. Piloting was performed in the same condition to the main study. In scoring the Nation's Vocabulary Levels Test, each correct answer was given one score, so the maximum score for each level was thirty the whole test score was ninety. The time limit for administration of the test was forty minutes. Then, the Multiple Intelligences Developmental Assessment Scales (MIDAS) was given to those who had passed the Nation's Vocabulary Levels Test. After that participants took a pretest of vocabulary. Pretest was designed based on the unfamiliar words of the texts which were in the treatment and it had a multiple-choice format. After twenty sessions that the treatment of the study was finished posttest was conducted to the same participants.

\section{Treatment of the Study}

The treatment which was used in this study was extensive reading. "Extensive reading is a reading (a) of large quantities of material or long texts; (b) for global or general understanding; (c) with the intention of obtaining pleasure from the text" (Hedge, 1985 pp. 68-70). Alessi and Dwyer (2008) agree that extensive reading due to its rapid expansion of vocabulary is one of the solutions for overcoming the obstacles of lack of vocabulary. About the level of texts in this study it should be mentioned that all the Twenty Three selected texts (short stories) were intermediate that conformed to the participants' proficiency level. It should be mentioned that because of the number of target words, one hundred and fifty, and also lack of time the assumed exposure to unfamiliar words in texts was only one time, in this study. The researcher selected the Twenty Three reading texts and read them aloud to the participants in class. In each twenty sessions of the treatment while the researcher wanted to read a text aloud, she gave the same copy of the text to the participants and after reading the text she collected them. Finally at the end of the treatment participants took the posttest of vocabulary, which was based on one hundred and fifty vocabulary items that were used in the texts and it was exactly the same as pretest of vocabulary.

\section{RESUlTS}

\section{A. Piloting Vocabulary Pretest-posttest}

Vocabulary Pretest and posttest which were exactly the same as each other were designed by the researcher so they needed to be piloted. Before administering the vocabulary pretest-posttest, it was piloted in the same condition to the main study to ensure its reliability for the study. The test was given to 80 intermediate female students, and they were asked not to use the dictionary. The reliability index of the vocabulary pretest-posttest $(r=.941)$ showed a high value. It is presented below in Table 1 .

TABLE 1.

CRONBACH ALPHA RELIABILITY (PILOT)

\begin{tabular}{|c|c|c|c|}
\hline \multicolumn{4}{|c|}{$\begin{array}{l}\text { Case Processing summary } \\
\end{array}$} \\
\hline \multirow{3}{*}{ Cases } & Valid & 80 & 100.0 \\
\hline & Excluded $^{\mathrm{a}}$ & 0 & .0 \\
\hline & Total & 80 & 100.0 \\
\hline
\end{tabular}

Reliability Statistics

\begin{tabular}{|l|l|l}
\hline Cronbach's Alpha & N of Items \\
\hline
\end{tabular}

\begin{tabular}{|l|l|l|l|l}
\hline .941 & 150
\end{tabular}

a. List wise deletion based on all variables in the procedure.

The descriptive statistics of the administration of the vocabulary pretest and posttest to the 42 EFL learners participating in this study appear below in Table 2. As is evident, the mean and standard deviation of the obtained pretest scores were 90.02 and 27.46 and the mean and standard deviation of obtained posttest scores were 109.60 and 25.30 , respectively. 
TABLE 2.

THE DESCRIPTIVE STATISTICS OF THE PARTICIPANTS' PERFORMANCE ON PRETEST AND POSTTEST. Descriptive Statistics

\begin{tabular}{|l|l|l|l|l|l|l|l|}
\hline & $\mathrm{N}$ & Minimum & Maximum & Mean & \multicolumn{2}{|l|}{ Std. Deviation } & \multicolumn{2}{|l|}{ Skewness } \\
\cline { 2 - 8 } & Statistic & Statistic & Statistic & Statistic & Statistic & Statistic & Std. Error \\
\hline Pretest & 42 & 37.00 & 141.00 & 90.02 & 27.46 & -.056 & .365 \\
Posttest & 42 & 43.00 & 142.00 & 109.60 & 25.30 & -1.045 & .365 \\
Valid N & 42 & & & & & & \\
(list wise) & & & & & & & \\
\hline
\end{tabular}

A one-sample independent t-test was performed in order to find whether there is a significant difference between the participants' performance on pretest and posttest. The results, as shown in Table 3, revealed that there is a significant difference $(\mathrm{t}=-3.39, \mathrm{p}<.05)$. Since the value in the Sig. (2tailed) column is less than .05 (Sig. (2tailed) $=.001<.05$ ) there is a significant difference in the mean scores of pretest and posttest. Also difference between mean of pretest (90.02) and posttest (109.60) showed significant increase in posttest.

TABLE 3.

INDEPENDENT SAMPLES T-TEST

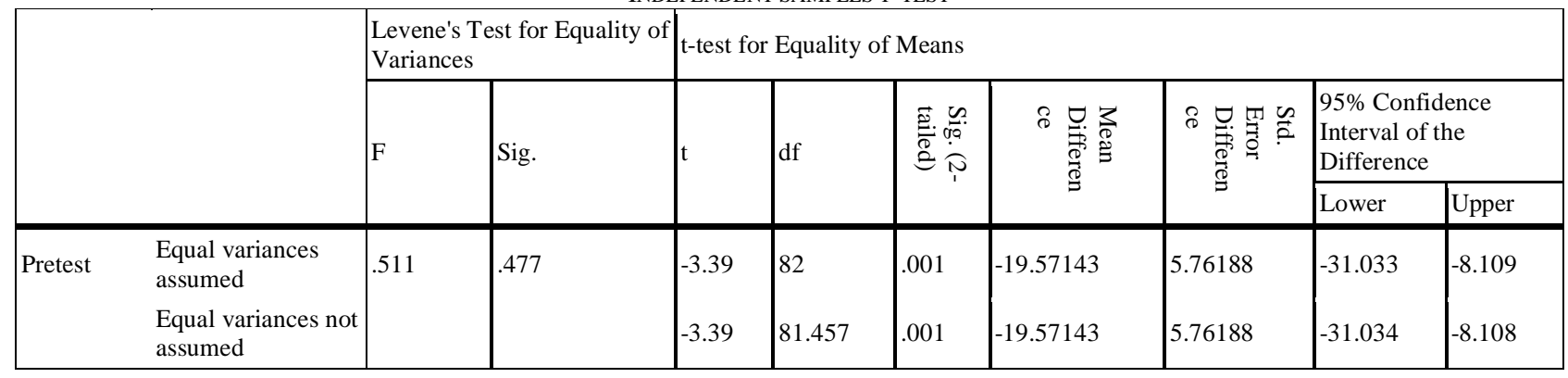

The first section of Independent Sample t-Test output box gives the results of Levene's test for equality of variances. It tested whether the variance of pretest and posttest was the same. Since the Sig. value was larger than .05 (Sig $=.477>.05)$ the results of the t-test with equal variances were assumed.

\section{B. Normality}

According to Field (2009), three assumptions should be met before one decides to use Pearson correlation test; the first one is that the data should be measured on an interval scale; the second one is that the subjects should be independent that is to say their performance on the test is not affected by the performance of other participants and the third one is the data should enjoy normal distribution.

The present data were measured on an interval scale and the subjects performed independently on the tests, i.e. the performance of any of the subjects on the test was not affected by the performance of the other subjects. The assumption of normality was also met. Bulmer (1979) suggests this rule about Skewness:

- If skewness is less than -1 or greater than +1 , the distribution is highly skewed.

- If skewness is between $-1 / 2$ and $+1 / 2$, the distribution is approximately symmetric

So according to Blumer's (1979) rule the distributions of all the items mentioned in Table 4 were distributed normally, except posttest which is highly skewed.

TABLE 4.

NORMALITY TESTS

\begin{tabular}{|l|l|l|l|l|l|}
\hline & $\mathrm{N}$ & Skewness & Kurtosis \\
\cline { 2 - 6 } & Statistic & Statistic & Std. Error & Statistic & Std. Error \\
\hline Pretest & 42 & -.056 & .365 & -.787 & .717 \\
\hline Posttest & 42 & -1.043 & .365 & .526 & .717 \\
\hline Musical & 42 & .353 & .365 & .492 & .717 \\
\hline Kinesthetic & 42 & -.011 & .365 & -.088 & .717 \\
\hline Math logical & 42 & -.006 & .365 & .010 & .717 \\
\hline Spatial & 42 & -.452 & .365 & .063 & .717 \\
\hline Linguistic & 42 & -.296 & .365 & -.479 & .717 \\
\hline Interpersonal & 42 & .040 & .365 & -.890 & .717 \\
\hline Intrapersonal & 42 & -.006 & .365 & -.200 & .717 \\
\hline Naturalist & 42 & .163 & .365 & -.128 & .717 \\
\hline Total MI & 42 & -.275 & .365 & .134 & .717 \\
\hline
\end{tabular}

\section{Investigation of the First Research Question}


The first research question attempted to see whether there is any significant relationship between incidental vocabulary learning and EFL learners' level of multiple intelligences. A Pearson correlation was run to probe any significant relationship between the incidental vocabulary learning and multiple intelligences. The results $(\mathrm{r}(40)=.32$, $\mathrm{P}=.036<.05$; represented a moderate effect size) and indicated that there is a significant relationship between the two variables. Since the significant $(\mathrm{P})$ is small (less than .05) the finding is statistically significant thus the first nullhypothesis as there is not any significant relationship between incidental vocabulary learning and multiple intelligences is rejected.

TABLE 5.

PEARSON CORRELATION INCIDENTAL VOCABULARY LEARNING WITH TOTAL MULTIPLE INTELLIGENCES

\begin{tabular}{|l|l|l|}
\hline \multicolumn{2}{|c|}{} & MI \\
\hline \multirow{3}{*}{ Posttest } & Pearson Correlation & $325^{*}$ \\
\cline { 2 - 3 } & Sig. (2-tailed) & .036 \\
\cline { 2 - 3 } & $\mathrm{N}$ & 42 \\
\hline \multirow{2}{*}{$*$. Correlation is significant at the 0.05 level (2-tailed). } \\
\hline
\end{tabular}

\section{Investigation of the Second Research Question}

The second research question aimed at investigating if there is any significant relationship between incidental vocabulary learning and a specific type of intelligences. To this end, a series of Pearson correlations were run to probe any significant relationships between the incidental vocabulary learning and the eight components of the multiple intelligences. Based on the results displayed in Table 6 it can be concluded that seven of the components of multiple intelligences showed non-significant relationships with the incidental vocabulary learning. The naturalist intelligence is the only significant component $(\mathrm{r}(40)=(40)=.39, \mathrm{P}=.01<.05$; it represented a moderate to large effect size). Thus it can be concluded that the naturalist intelligence is the only component of MI that showed significant relationship with incidental vocabulary learning.so the second null-hypothesis was also rejected.

TABLE 6.

COMPONENTS OF MULTIPLE INTELLIGENCES WITH INCIDENTAL VOCABULARY LEARNING

\begin{tabular}{|c|c|c|}
\hline & & Posttest \\
\hline \multirow{3}{*}{ Musical } & Pearson Correlation & .248 \\
\hline & Sig. (2-tailed) & .113 \\
\hline & $\mathrm{N}$ & 42 \\
\hline \multirow{3}{*}{ Kinesthetic } & Pearson Correlation & .173 \\
\hline & Sig. (2-tailed) & .272 \\
\hline & $\mathrm{N}$ & 42 \\
\hline \multirow{3}{*}{ Math-Logical } & Pearson Correlation & .231 \\
\hline & Sig. (2-tailed) & .142 \\
\hline & $\mathrm{N}$ & 42 \\
\hline \multirow{3}{*}{ Spatial } & Pearson Correlation & .258 \\
\hline & Sig. (2-tailed) & .099 \\
\hline & $\mathrm{N}$ & 42 \\
\hline \multirow{3}{*}{ Linguistic } & Pearson Correlation & .246 \\
\hline & Sig. (2-tailed) & .117 \\
\hline & $\mathrm{N}$ & 42 \\
\hline \multirow{3}{*}{ Interpersonal } & Pearson Correlation & .093 \\
\hline & Sig. (2-tailed) & .558 \\
\hline & $\mathrm{N}$ & 42 \\
\hline \multirow{3}{*}{ Intrapersonal } & Pearson Correlation & .231 \\
\hline & Sig. (2-tailed) & .140 \\
\hline & $\mathrm{N}$ & 42 \\
\hline \multirow{3}{*}{ Naturalist } & Pearson Correlation & $.392^{*}$ \\
\hline & Sig. (2-tailed) & .010 \\
\hline & $\mathrm{N}$ & 42 \\
\hline
\end{tabular}

\section{Reliability}

In this part the reliability of the pretest and posttest of incidental vocabulary learning and multiple intelligences questionnaire was assessed. The K-R21 reliability indices for the pretest and posttest of incidental vocabulary leaning are .96 .

TABLE 9.

K-R21 RELIABILITY INDICES PRETEST AND POSTTEST OF INCIDENTAL VOCABULARY LEARNING

\begin{tabular}{|l|l|l|l|l|}
\hline & N of Items & Mean & Variance & K-R21 \\
\hline Pretest & 150 & 90.02 & 754.121 & .96 \\
\hline Posttest & 150 & 109.57 & 641.568 & .96 \\
\hline
\end{tabular}


Table 10 displays the Cronbach Alpha reliability indices for the eight components of the multiple intelligences and the total MI. Cronbach's Alpha is the most popular method of examining reliability; a high correlation between the different items will indicate they are measuring the same thing as there will be only small values for the error. A low correlation will indicate that there are a lot of errors and the items are not reliably measuring the same thing. Cronbach's Alpha ranges from 0 for a completely unreliable test to 1 for a completely reliable test. The reliability indices in this research ranged from a high of .93 for the total MI to a low of . 72 for the spatial intelligence

TABLE 10.

CRONBACH ALPHA RELIABILITY OF MI

\begin{tabular}{|l|l|l|}
\hline & Cronbach's Alpha & N of Items \\
\hline Musical & .788 & 14 \\
\hline Kinesthetic & .781 & 13 \\
\hline Math-Logical & .812 & 17 \\
\hline Spatial & .726 & 15 \\
\hline Linguistic & .739 & 20 \\
\hline Interpersonal & .795 & 18 \\
\hline Intrapersonal & .769 & 9 \\
\hline Naturalist & .779 & 13 \\
\hline Total MI & .939 & 119 \\
\hline
\end{tabular}

\section{DisCUSSION AND CONCLUSION}

Recently MI theory has drawn lots of attention toward itself. It has become an important issue in language pedagogy, curriculum designing and assessment. It sheds a light on uniqueness of each individual. Gardner's (1983) theory of multiple intelligences indicates that language learning is a complex interaction of a number of intelligences. The importance of using intelligence became clear for everyone who works in the field of language teaching and learning. Dobbs (2002) insists upon this fact that when students have a chance to learn through their strengths, they may be more successful in learning. In spite of the increasing number of research on MI, the relationship between MI and different skills and sub skills of language is still new in Iran. There are some studies which were done in the area of intelligence and different components of language. For example in a study, Naeini and Pandian (2010) investigated the relationship between MI and listening proficiency. They found that there is no significant relationship between MI and listening. Zohourian (2009) confirmed that there was a significant relationship between advanced Iranian EFL learner's vocabulary learning and their multiple intelligences.

This study aimed at investigating whether there is any significant relationship between MI and incidental vocabulary learning among Iranian intermediate EFL learners. As the results showed there is a significant relationship between MI and incidental vocabulary learning. Furthermore among different domains of intelligences, naturalist intelligence has statistically significant relationship with incidental vocabulary learning.

Furthermore, findings of the present study can be supported by Razmjoo et al.'s (2009) study that investigated the relationship between MI, vocabulary learning knowledge and vocabulary learning strategies among the Iranian EFL learners. Their study revealed that there is a significant relationship between MI and vocabulary learning knowledge. Besides this finding it has been mentioned that linguistic and naturalist intelligences have a significant relationship with vocabulary learning knowledge. The results of Razmjoo et al.'s study are consistent with the result of this study. In the both studies one of the variables were MI, in this study the relation between MI and incidental vocabulary learning were discussed and it was found that in addition to significant relationship between MI and incidental vocabulary learning, there is a significant relationship between naturalist intelligence and incidental vocabulary learning . In both studies the naturalist intelligence is seen in the results.

As a final point, some suggestions are provided for the researchers who are interested in this field of inquiry. In this study the relationship between MI as an emergent model in language teaching and learning and incidental vocabulary learning as an enjoyable, contextual way of vocabulary learning were scrutinized. As it was discussed in this study due to the findings of the study, it will be effective to apply the result of this study in designing syllabus and developing educational curriculum whereupon EFL teachers can enjoy the learners' intelligences in their language teaching and learners can learn better and easier which leads to having more active and creative EFL learners. In so far as the participants of this study were intermediate adult students, a similar research on students of different age range and language proficiency level can be done. Also other research studies can be conducted to investigate how much does MI theory work in Iranian classes or what the teachers' and students' belief is toward the MI theory and its application in different areas of second language learning.

\section{REFERENCES}

[1] Alessi, S., \& Dwyer, A. (2008). Vocabulary assistance before and during reading. Reading in a Foreign Language, 20, 246-263.

[2] Allen, F. V. (1983). Techniques in teaching vocabulary. Oxford: Oxford University Press

[3] Beglar, D., \& Hunt, A. (2005). Six principles for teaching foreign language vocabulary: A commentary on Laufer, Meara, and Nation's "Ten best ideas". The language teacher 29, 7-10. 
[4] Blumer, M. G. (1979). Principles of statistics. New York: Dover.

[5] Dobbs, V. (2002). The relationship between implementation of multiple intelligences theory in the curriculum and student academic achievement at a seventh-grade at-risk alternative school. Dissertation Abstract International, 62.

[6] Field, A. (2009). Discovering statistics using SPSS. Sage publications.

[7] Gardner, H. (1983). Frames of mind: The theory of multiple intelligences. New York: Basic Books.

[8] Gardner, H., \& Hatch, T. (1989). Multiple intelligences go to school: Educational implications of the theory of multiple intelligences. Educational Research, 18, 4-9. Doi: 10.3102/0013189x01800804.

[9] Gass, S. (1999). Incidental vocabulary learning: Discussion. SSLA, 21, 319-333.

[10] Griffiths, C. (2003). Patterns of language learning strategy use. System 31, 367-383.

[11] Hedge, T. (1985). Using readers in language teaching. London:Macmillan.

[12] Hoerr, T. R. (2000). Becoming a multiple intelligence school. Virginia: Association for supervision and curriculum development.

[13] $\mathrm{Hu}$, M., \& Nation, I.S.P. (2000) Unknown vocabulary density and reading comprehension. Reading in a foreign language, 13, 403-430.

[14] Huckin, T., \& Coady, J. (1999). Incidental vocabulary acquisition in a second language. Studies in second language acquisition. 21, 181-193. Doi: 10. 1017/s0272263199002028.

[15] Hulstijin, J. H. (2011). Incidental learning in second language acquisition. The encyclopedia of applied linguistic, 1-5.

[16] Mosallanejad, P. \& Khaghazgarian, N. (2012). English through reading touching stories. Tehran: Sepahan.

[17] Naeini, B. M., \& Pandian, A. (2010). On the relationship of Multiple Intelligences with listening proficiency and attitudes among Iranian EFL university students. TESL Canada journal, 28, 97- 114.

[18] Nation, I.S.P. (1983). Testing and teaching vocabulary. Guidelines 5, 12-25.

[19] Nation, I.S.P. (1990). Teaching and learning vocabulary. New York: Heinle and Heinle.

[20] Nation, I.S. P. (2001). Learning vocabulary in another language. Cambridge: Cambridge University Press.

[21] Nation, I.S.P. (2008). Teaching vocabulary. Boston:Heinle.

[22] Nelson, K. N. (1998). Developing students' multiple intelligences. New York: Scholastic.

[23] Paribakht, S., \& Wesche, M. (1999). Reading and incidental L2 vocabulary acquisition (an introspective study of lexical inferencing). Studies in Second Language Acquisition, 21, 195-224.

[24] Qian, D.D. (2002). Investigating the relationship between vocabulary knowledge and academic reading performance: an assessment perspective. Language Learning, 52, 513-536.

[25] Razmjoo, S. A., Sahragard, R. \& Sadri, M. (2009). On the relationship on the relationship between MI, vocabulary learning knowledge and vocabulary learning strategies among the Iranian EFL learners. The Iranian EFL journal, 3, 82-110.

[26] Schmitt, N., Schmitt, D., \& Clapham, C. (2001). Developing and exploring the behaviour of two new versions of the Vocabulary Levels Test. Language Testing, 18, 55-88. Doi: 10.1177/02655322010180013.

[27] Shearer, C. B. (1996). Multiple intelligences developmental assessment scales (MIDAS). United States of America: Author.

[28] Zohourian, T. (2009). The relationship between learners' use of vocabulary learning strategies and their multiple intelligences. Unpublished master's thesis, Islamic Azad University, Science and Research Branch, Tehran, Iran.

Ali Akbar Khomeijani Farahani has a phD and is a professor of linguistics at the university of Tehran. He has been a faculty member for 22 years and has published papers nationally and internationally. His research interests are teaching methodology, first language acquisition and second language acquisition.

EInaz Latifi Kalkhoran got her MA in English Language Teaching. She has taught English in language schools and institutes for several years. Her research interests lie in second language teaching and learning and discourse analysis. 